\title{
KOMPENSASI, BUDAYA ORGANISASI DAN KEPUASAN TENAGA KEPENDIDIKAN UNIVERSITAS SINGAPERBANGSA KARAWANG
}

\author{
Asep Jamaludin \\ Fakultas Bisnis dan Ilmu Sosial UBP Karawang \\ Asep.jamaludin@ubpkarawang.ac.id
}

\begin{abstract}
ABSTRAK
Tujuan penelitian ini untuk memperoleh bukti-bukti empirik dan menemukan kejelasan fenomena serta kesimpulan tentang Pengaruh Kompensasi dan Budaya Organisasi Terhadap Kepuasan Kerja Tenaga kependidikan pada Universitas Singaperbangsa Karawang.

Metode penelitian yang digunakan adalah metode deskriftif kuantitatif. Teknik sampling yang digunakan adalah metode sensus. Teknik analisis data yang digunakan yaitu teknik analisis korelasi yaitu untuk mengetahui derajat keeratan hubungan variabel penelitian dan tehnik analisis jalur.

Hasil analisis secara deskriftif menunjukan bahwa variabel kompensasi berada pada skala setuju, variabel budaya organisasi berada pada skala setuju, sedangkan variable Kepuasan Kerja Tenaga kependidikan berada pada skala puas

Hasil analisis secara verifikatif menunjukan bahwa hubungan korelasional antara kompensasi dan budaya organisasi memiliki hubungan cukup kuat dengan nilai korelasi sebesar 0,42, pengaruh parsial antara kompensasi terhadap kepuasan kerja sebesar 0,172 sedangkan pengaruh parsial budaya organisasi terhadap kepuasan kerja sebesar 0,730. Adapun hasil analisis secara simultan menunjukan bahwa kompensasi dan budaya organisasi berpengaruh terhadap kepuasan kerja sebesar 0,6679 atau sebesar 66,79\%.

Kata kunci : kompensasi, budaya organisasi, kepuasan kerja
\end{abstract}

\section{ABSTRAC}

The purpose of this study to obtain empirical evidence and found the clarity of the phenomenon and the conclusion of the Compensation and Organizational Culture Influence on Job Satisfaction education personnel at the University of Singaperbangsa Karawang.

The method used is descriptive and verification methods. The sampling technique used is a census method. The data analysis technique used is the technique of correlation analysis is to determine the degree of closeness of relationship research variables and path analysis techniques.

The results of descriptive analysis showed that the variable compensation is the agreed scale, organizational culture variables are on the scale agreed, while the variable job satisfaction education personnel is in scale satisfied.

The results of the verification analysis showed that the correlation relationship between compensation and organizational culture has a strong enough relationship with a correlation value of 0.42 , the partial effect of compensation on job satisfaction of 0.172 while the partial effect of organizational culture on job satisfaction of 0.730. The simultaneous analysis results showed that 
compensation and organizational culture influence on job satisfaction of 0.6679 or $66.79 \%$ of.

Keywords: compensation, organizational culture, job satisfaction

\section{PENDAHULUAN}

Undang-Undang Republik Indonesia Nomor 20 Tahun 2003 tentang Sistem Pendidikan Nasional, pada pasal 39 ayat 1 (satu) menjelaskan bahwa "Tenaga kependidikan bertugas melaksanakan administrasi, pengelolaan, pengembangan, pengawasan, dan pelayanan teknis untuk menunjang proses pendidikan pada satuan pendidikan".

Pendidik dan tenaga kependidikan berkewajiban untuk (1) menciptakan suasana pendidikan yang bermakna, menyenangkan, kreatif, dinamis, dan dialogis; (2) Mempunyai komitmen secara profesional untuk meningkatkan mutu pendidikan; dan (3) memberi teladan dan menjaga nama baik lembaga, profesi, dan kedudukan sesuai dengan kepercayaan yang diberikan kepadanya.

Universitas Singaperbangsa Karawang (Unsika) merupakan PTS yang alih status menjadi PTN tahun 2015/2016. memiliki mahasiswa aktif sebanyak 12.060 yang didukung oleh keberadaan tenaga kependidikan/tenaga administrasi yang sangat penting dalam keberhasilan proses pembelajaran sehingga mampu menciptakan sarjana-sarjana yang siap pakai, memiliki kemampuan akademis dan praktis serta mandiri.

Unsika masih memiliki permasalahan internal tenaga kependidikan, diantaranya ketidak sesuaian struktur pegawai antara peraturan pegawai yang menyatakan bahwa tenaga kependidikan minimal berpendidikan Strata Satu (S1) namun dalam kenyataanya masih menerima karyawan (tenaga kependidikan) berpendidikan SLTA, terlihat dari data karyawan di bawah ini yang menunjukan bahwa dari jumlah karyawan sebanyak 120 orang (tahun 2015) masih terdapat karyawan yang berpendidikan SLTA sebanyak 21 orang, D2 sebanyak 1 orang, D3 sebanyak 12 orang. Disisi lain pada tahun 2014 Unsika belum memiliki sistem pelatihan dan jenjang karir dan jenjang kompensasi yang jelas yang dapat dilaksanakan secara konsisten sehingga diperkirakan akan menghasilkan budaya 
kerja dan kepuasan kerja yang tidak seragam diantara pegawainnya.

Penelitian Agus Dwi Nugroho, Kunartinah (2012) sumbangan terbesar terhadap kepuasan kerja karywan adalah variabel kompensasi. Menurut Simamora kompensasi meliputi kembalian-kembalian financial dan jasa-jasa serta tunjangan-tunjangan yang diterima oleh sebagai ganti kontribusi mereka kepada organisasi.

Kepuasan kerja adalah keadaan emosional yang menyenangkan atau tidak menyenangkan dimana para pekerja memandang pekerjaannya. Kepuasan kerja merupakan cerminan dari perasaan pekerja terhadap pekerjaannya. Hal ini tampak dalam sikap positif pekerja terhadap pekerjaan yang dihadapi dan lingkungannya. Sebaliknya, pekerja yang tidak puas akan bersikap negatif terhadap pekerjaan dengan bentuk yang berbeda- beda satu dengan yang lainnya.

Selain itu kepuasan kerja adalah suatu sikap umum terhadap pekerjaan seseorang sebagai perbedaan antara banyaknya kompensasi yang diterima karyawan dan banyaknya yang diyakini yang harus diterima. Oleh karena, itu salah satu cara terbaik untuk meningkatkan kepuasan kerja pegawai adalah dengan menghubungkan kompensasi dengan kepuasan pegawai. Jika program kompensasi dirasakan adil dan kompetitif bagi pegawai, maka organisasi akan lebih mudah untuk menarik pegawai yang potensial, mempertahankannya dan memotivasi pegawai agar lebih meningkatkan kinerjanya sehingga produktivitas meningkat dan kinerja organisasi juga akan meningkat.

Menurut Hasibuan (2007) Kepuasan kerja adalah sikap emosional yang menyenangkan dan mencintai pekerjaannya. Adapun dimensi kepuasan kerja yang digunakan dalam penelitian ini yaitu 1) pekerjaan yang menantang; 2) ganjaran yang pantas; 3) kondisi kerja yang mendsukung; 4) pimpinan/ rekan kerja yang mendukung; 5) kesesuaian pribadi dengan pekerjaan

Kepuasan kerja merupakan kriteria efektivitas yang mengacu kepada keberhasilan organisasi dalam memenuhi kebutuhan karyawan atau anggotanya kesejahteraan, dan sebagainya" (Tika, 2005:130). Menurut Luthans (2006:175) Kepuasan kerja dalam bekerja adalah apa yang dinikmati dalam pekerjaan dengan memperoleh hasil tujuan kerja, penempatan, perlakuan, dan suasana lingkungan 
kerja yang baik. Karyawan yang lebih suka menikmati kepuasan kerja dalam pekerjaan ini akan lebih mengutamakan pekerjaannya daripada balas jasa dari pelaksanaan tugas-tugasnya". Sedangkan Moorse dalam Panggabean (2002:128) mengemukakan "Pada dasarnya, kepuasan kerja tergantung kepada apa yang diinginkan seseorang dari pekerjaanya dan apa yang mereka peroleh”. Kemudian menurut Rivai (2008:222) bahwa sesuai kodratnya, kebutuhan manusia sangat beraneka ragam, baik jenis maupun ragamnya, bahkan manusia memiliki kebutuhan yang cenderung tak terbatas". Artinya, kebutuhan selalu bertambah dari waktu ke waktu dan manusia selalu berusaha dengan segala kemampuannya untuk memuaskan kebutuhan tersebut. Lebih lanjut Rivai (2008:223) mengemukakan, "Kepuasan kerja pada dasarnya merupakan sesuatu yang bersifat individual. Setiap Individu memiliki tingkat kepuasan yang berbeda-beda sesuaidengan sistem nilai yang berlaku pada dirinya".

Luthans (2006) menyatakan bahwa ada sejumlah faktor yang mempengaruhi kepuasan kerja. Hal-hal utama dengan mengingat dimensi-dimensi paling penting yaitu gaji, pekerjaan itu sendiri, promosi, pengawasan, kelompok kerja dan kondisi kerja. Selanjutnya Nelson and Quick (2006) mengungkapkan bahwa kepuasan kerja dipengaruhi 5 dimensi spesifik dari pekerjaan yaitu gaji, pekerjaan itu sendiri, kesempatan promosi, supervisi dan rekan kerja.

Faktor lain yang berpengaruh terhadap kepuasan kerja pegawai adalah budaya organisasi. Budaya organisasi merupakan system penyebaran kepercayaan dan nilai-nilai yang berkembang dalam suatu organisasi dan mengarahkan prilaku anggota-anggotannya. Budaya organisasi menjadi instrumen keunggulan kompetitif yang utama karena budaya organisasi mendukung strategi organisasi dan dapat menjawab atau mengatasi tantangan lingkungan dengan cepat dan tepat (Soedjono, 2005 dalam Dhanny Permana, 2008). Pada penelitian Soedjono (2005) menyatakan terdapat pengaruh budaya organisasi terhadap kepuasan kerja, sedangka pada penelitian Koesmono (2005) juga mendapatkan hasil bahwa budaya organisasi berpengaruh terhadap motivasi dan kepuasan kerja. Demikianjuga yang disampaikan oleh Kirk L Rogga (2001) dalam Dhanny 
Permana (2008) menyatakan bahwa budaya organisasi dapat meningkatkan kepuasan kerja.

Kompensasi adalah semua pendapatan yang berbentuk uang, barang langsung atau tidak langsung yang diterima karyawan sebagai imbalan atas jasa yang diberikan kepada perusahaan (Hasibuan Malayu S.P., 2003:118), terdiri dari (1) Kompensasi langsung: a) gaji tetap (fix): gaji pokok dan upah; b) gaji tidak tetap (variabel): bonus dan komisi. Gaji Tetap (Fix) adalah bayaran yang konsisten dari satu periode ke periode lain dengan tidak memandang jumlah jam kerja. Gaji Tidak Tetap (Variable) adalah: kompensasi yang dikaitkan dengan kinerja individual, kelompok, dan/atau organisasi; (2) Kompensasi tidak langsung (tunjangan): imbalan tidak langsung (askes, uang cuti, pensiun, dll) yang diberikan kepada karyawan sebagai bagian dari keanggotaannya di organisasi

Untuk menjelaskan budaya organisasi yang terjadi di Unsika, jika didasarkan kepada pendapat Robbins (2008:208), dapat dilihat dari sepuluh faktor utama, yaitu inisiatif individu, toleransi terhadap tindakan berisiko, arah sasaran organisasi, integritas, dukungan manajemen, kontrol, identitas, sistem imbalan, toleransi terhadap konflik dan pola-pola komunikasi. Berdasarkan dimensi tersebut belum menunjukan penciptaan budaya organisasi yang baik, terlihat dari kegiatan rapat koordinasi antara tenaga kependidikan dan pimpinan tidak pernah dilaksanakan, gagasan-gagasan inovatif dari karyawan tidak diakomodasi dengan baik hal ini terlihat dengan tidak adanya peraturan yang menyatakan memberikan penghargaan kepada karyawan yang menyampaikan gagasan inovatif.

Budaya Organisasi menurut Schein dalam Luthans (2006:124) Budaya organisasi adalah pola asumsi dasar diciptakan atau dikembangkan oleh kelompok tertentu saat mereka menyesuaikan diri dengan masalah-masalah eksternal dan integrasi internal yang telah bekerja cukup baik serta dianggap berharga, dan karena itu diajarkan pada anggota baru sebagai cara yang benar untuk menyadari, berpikir dan merasakan hubungan dengan masalah tersebut. Glaser dalam Kreitner dan Kinicki (2005:323) menyatakan "Budaya organisasi seringkali digambarkan dalam arti dimiliki bersama. Pola-pola dari kepercayaan, simbol-simbol, ritualritual dan mitos-mitos yang berkembang dari waktu ke waktu dan berfungsi 
sebagai perekat yang menyatukan organisasi”. Beraneka ragamnya bentuk organisasi atau perusahaan, tentunya mempunyai budaya yang berbeda hal ini wajar karena lingkungan organisasinya berbeda-beda pula misalnya perusahaan jasa, manufaktur, dan trading.

Robbins dalam Umar (2010:208), untuk menilai kualitas budaya suatu organisasi dapat dilihat dari sepuluh faktor utama, yang akan dijadikan dimensi dalam penelitian ini yaitu : 1) inisiatif individu; 2) tolelansi tindakan berisiko; 3) arah; 4) integrasi; 5) dukungan manajemen; 6) control; 7) identitas; 8) sisitem imbalan; 9) toleransi terhadap konflik dan 10) pola komunikasi.

Tujuan dari penelitian ini adalah untu menjelaskan pelaksanaan kompensasi, budaya organisasi, kepuasan kerja tenaga kependidikan Unsika serta untuk menjelaskan hubungan diantara variable tersebut.

\section{METODE PENELITIAN}

Penelitian ini termasuk dalam penelitian deskriptif kuantitatif. Menurut Sugiyono (2008:5), penelitian deskriptif adalah penelitian yang dilakukan untuk mengetahui nilai variabel mandiri, baik satu variabel atau lebih (independen) tanpa membuat perbandingan, atau menghubungkan dengan variabel yang lain. Penelitian kuantitatif dapat diartikan sebagai metode penelitian yang digunakan untuk meneliti populasi atau sampel tertentu, dan analisis data bersifat statistik dengan tujuan untuk menguji hipotesis yang telah ditetapkan.

Secara deskriptif penelitian ini bertujuan untuk memperoleh gambaran mengenai variabel kompensasi dan budaya organisasi sebagai variable bebasnya dan variabel kepuasan kerja sebagai variabel terikat. Sedangkan secara verifikatif bertujuan untuk menguji hipotesis dengan perhitungan statistik.

Ada tiga variabel dalam penelitian ini yaitu dua variabel Eksogen $\left(\mathrm{X}_{1}\right.$ dan $\mathrm{X}_{2}$ ) dan satu variabel endogen $(\mathrm{Y})$. Dalam hal ini variabel $\mathrm{X}_{1}$ adalah kompensasi dan Variabel $\mathrm{X}_{2}$ adalah budaya organisasi merupakan variabel yang dihipotesiskan mempengaruhi variabel Y (kepuasan kerja). 
Populasi dalam penelitian ini adalah tenaga kependidikan Universitas Singaperbangsa Karawang berjumlah 120 orang (tahun 2015) dan jumlah sampelnya sebanyak 100 orang.

Untuk menjelaskan kondisi lapangan pada setiap variable maka dilakuan analisis deskriptif melalui analisis distribusi frekuensi dan rentang sekala. Analisis kuantitatif dengan metode analisis jalur untuk melihat pengaruh eksogen terhadap variabel endogen baik secara parsial maupun secara simultan.

\section{HASIL PENELITAN DAN PEMBAHASAN}

Kondisi tenaga kependidikan Unsika yang menjadi responden dalam penelitian ini terdiri dari $41 \%$ Perempuan dan $59 \%$. Berdasarkannya usianyadan statusnya dijelaskan pada grafik 1 dan 2.

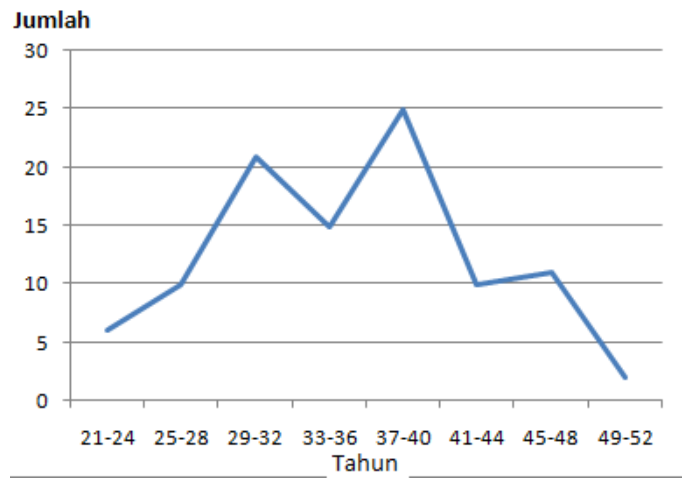

Grafik 1

Jumlah Responden Berdasarkan

Usia

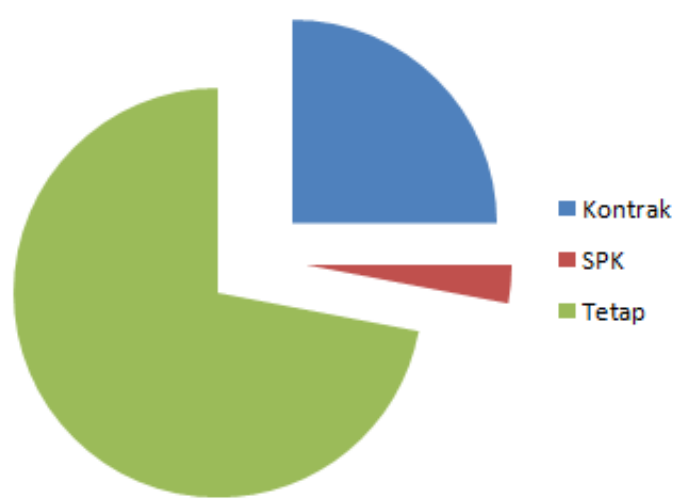

Grafik 2

Jumlah Responden Berdasarkan Status

Pendidikan responden mayoritas S1 (strata satu) sebanyak 64\% sedangkan terbanyak kedua lulusan SLTA sebanyak 22\%, secara rinci dapat terlihat pada tabel 1 .

Tabel 1 : Jumlah Responden Berdasarkan Pendidikan

\begin{tabular}{c|ccc} 
NO & PENDIDIKAN & JUMLAH & PERSENTASE \\
\hline $\mathbf{1}$ & Sederajat SLTA & 22 & $22,0 \%$ \\
$\mathbf{2}$ & D1 & 0 & $0,0 \%$ \\
$\mathbf{3}$ & D2 & 0 & $0,0 \%$ \\
$\mathbf{4}$ & D3 & 10 & $10,0 \%$ \\
$\mathbf{5}$ & S1 & 64 & $64,0 \%$
\end{tabular}




\begin{tabular}{c|c|cc}
6 & S2 & 4 & $4,0 \%$ \\
& TOTAL & 100 & $100 \%$ \\
\hline
\end{tabular}

Sumber : Data Primer, dianalisis 2016

Hasil uji validitas variabel kompensasi terhadap kuisoner yang diujicobakan kepada 30 responden dan semua pernyataan dan kuesioner yang dugunakan untuk seluruh variable adalah valid dan realiable. Begitu pula uji normalitas sampel terdistribusi normal sehgingga alat ukur yang digunakan dapat digunakan ntuk analisis dalam penelitian ini.

\section{Analisis Deskriptif}

Berikut ini rekapitulasi analisis deskriptif Kompensasi yang diberikan, kualitas budaya organisasi dan tingkat kepuasan kerja tenaga kependidikan di Universitas SIngaperbangsa Karawang

Tabel 2 : Rekapitulasi Deskriipsi Kompensasi, Budaya Organisasi dan Kepusan kerja

\begin{tabular}{|l|l|l|l|}
\hline No & \multicolumn{1}{|c|}{ Variabel dan Dimesi } & \multicolumn{1}{|c|}{$\begin{array}{c}\text { Rata- } \\
\text { rata Skor }\end{array}$} & Keterangan \\
\hline 1 & $\begin{array}{l}\text { Kompensasi } \\
\text { - Kompensasi Langsung } \\
\text { - Kompensasi Tidak Langsung } \\
\text { - Kompensasi Non Finansial }\end{array}$ & 293,48 & Cukup Baik \\
\hline 2 & $\begin{array}{l}\text { Budaya Organisasi } \\
\text { - Inisiatif Individu } \\
\text { - Toleransi Terhadap Tindakan Beresiko } \\
\text { - Arah } \\
\text { - Integrasi } \\
\text { - Dukungan Manajemen } \\
\text { - Identitas } \\
\text { - Sistem imbalan } \\
\text { - Toleransi terhadap konflik } \\
\text { - Pola Komunikasi }\end{array}$ & 385,44 & Setuju \\
\hline 3 & $\begin{array}{l}\text { Kepuasan Kerja } \\
\text { - Pekerjaan yang menantang } \\
\text { - Ganjaran yang Pantas } \\
\text { - Kondisi Kerja yang Mendukung } \\
\text { - Dukukan Pimpinan/ Rekan Kerja } \\
\text { - Kesesuaian Pribadi dengan Pekerjaan }\end{array}$ & & \\
\hline
\end{tabular}

Keterangan Skala Skor: 


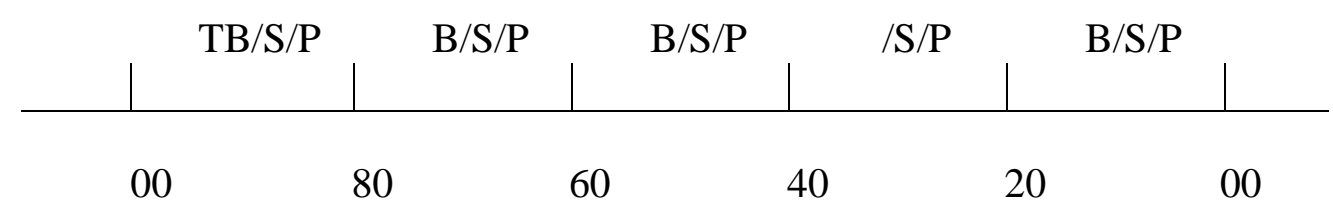

Dari Tabel 2 di atas menunjukan bahwa variabel kompensasi berada pada skala Cukup Baik, budaya organisasi berada pada skala Baik dan kepuasan kerja berada pada skala Memuaskan.

\section{Analisis Jalur}

Pengaruh secara parsial variabel kompensasi dan budaya organisasi terhadap variabel kepuasan kerja dapat digambarkan seperti yang tampak dalam gambar 2.

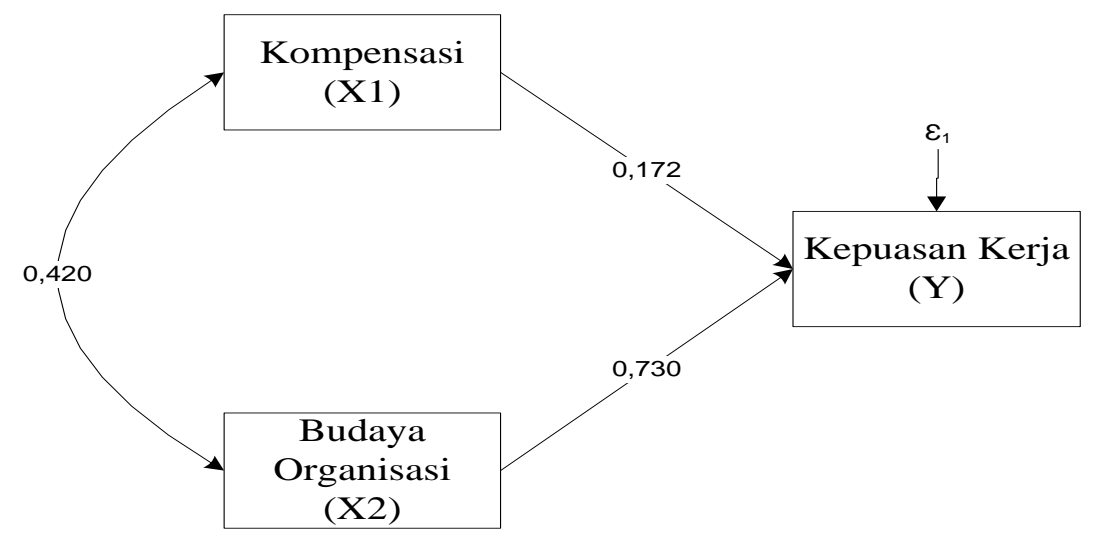

\section{Gambar 3. Pengaruh Parsial dan Simultan Kompensasi dan Budaya Organisasi Terhadap Kepuasan Kerja}

Dari gambar 3 di atas, dapat besaran derajat asosiatif atau koefisien jalur dari masing - masing variabel bebas terhadap variabel terikat dimana variabel budaya organisasi mempunyai koefisien jalur lebih tinggi dibandingkan dengan variabel kompensasi.

Untuk persamaan jalurnya, yaitu :

$$
Y=0,172 X_{1}+0,730 X_{2}+\varepsilon_{1}
$$

Dimana :

$$
\mathrm{Y}=\text { Kepuasan Kerja }
$$




$$
\begin{aligned}
& \mathrm{X}_{1}=\text { Kompensasi } \\
& \mathrm{X}_{2}=\text { Budaya Organisasi } \\
& \boldsymbol{\varepsilon}_{1}=\text { Pengaruh variabel lain }
\end{aligned}
$$

Pengaruh langsung dan tidak langsung secara bersamaan dari variabel kompensasi dan budaya organisasi terhadap variabel kepuasan kerja adalah sebagai berikut :

a. Pengaruh langsung variabel kompensasi terhadap kepuasan kerja sebesar 2,96 $\%\left(\rho_{\text {yx } 1}^{2}\right)$ dan Pengaruh langsung variabel budaya organisasi terhadap kepuasan kerja sebesar 53,29\% $\left(\rho^{2} \mathrm{yx} 2\right)$

b. Total Pengaruh tidak langsung variabel kompensasi terhadap kepuasan kerja sebesar 5,27\% dan Total pengaruh tidak langsung variabel budaya organisasi terhadap kepuasan kerja sebesar 5,27\%.

Besaran pengaruh total dari variabel kompensasi dan budaya organisasi terhadap variabel kepuasan kerja dinyatakan oleh besaran koefisien determinasi $\left(\mathrm{R}_{\mathrm{YX}}\right)^{2}$ sebesar $66,79 \%$ sedangkan pengaruh variabel lain di luar model adalah sebesar $33,21 \%$.

\section{Tabel 3 : Pengaruh Langsung dan Tidak Langsung Variabel Kompetensi} Guru dan Fasilitas Pembelajaran Terhadap Kinerja Guru

\begin{tabular}{ccccc} 
Variabel & $\begin{array}{c}\text { Pengaruh Langsung } \\
\text { Kepuasan Kerja }\end{array}$ & \multicolumn{2}{c}{ Pengaruh Tidak Langsung } & Total \\
\cline { 3 - 4 } & & Kompensasi & $\begin{array}{c}\text { Budaya } \\
\text { Organisasi }\end{array}$ & \\
\hline Kompensaruh \\
Budaya & 0,0296 & - & 0,0527 & 0,0823 \\
Organisasi & 0,5329 & 0,0527 & - & 0,5856 \\
& & & 0,6679 \\
\hline
\end{tabular}

Hasil penelitian verifikatif dapat diuraikan bahwa Hubungan antara Kompensasi $\left(\mathrm{X}_{1}\right)$ dengan budaya organisasi $\left(\mathrm{X}_{2}\right)$ sebesar 0,420 dan mempunyai tingkat hubungan yang cukup kuat. Ini menunjukan bahwa jika kompensasi 
meningkat maka budaya organisasi juga akan meningkat. Sebaliknya jika kompensasi menurun budaya organisasi juga menurun.

Pengaruh parsial kompensasi $\left(\mathrm{X}_{1}\right)$ terhadap kepuasan kerja $(\mathrm{Y})$ yaitu sebesar 0,172 dan budaya organisasi $\left(\mathrm{X}_{2}\right)$ terhadap kepuasan kerja $(\mathrm{Y})$ yaitu sebesar 0,730. Berdasarkan pengolahan data tersebut menunjukan bahwa nilai $0,172<$ 0,730, maka dapat dinyatakan bahwa budaya organisasi lebih besar dan lebih dominan memberikan kontribusi terhadap kepuasan kerja dibandingkan kompensasi. Hal ini mengindikasikan bahwa para pegawai lebih dapat meningkat keupasan kerjanya dengan meningkatkan budaya organisasi.

Total pengaruh kompensasi (X1) dan budaya organisasi (X2) terhadap kepuasan kerja sebesar 0,6679 atau sebesar 66,79\%. Berdasarkan hasil penelitian ini menunjukan bahwa kompensasi dan budaya organisasi memiliki kontribusi terhadap kepuasan kerja (Y) sebesar $66,79 \%$ sedangkan sisanya 0,3321 atau sebesar 33,21\% merupakan pengaruh kontribusi variabel lain $(\varepsilon)$ yang tidak diteliti. Kompensasi (X1) berpengaruh signifikan terhadap kepuasa kerja (Y), dengan kriteria uji nilai Sig. $(0,000)<\alpha(0,05)$. Artinya Ho ditolak. Hal ini dapat dijelaskan bahwa kompensasi mempunyai nilai signifikansi atau bermakna terhadap kepuasan kerja. Budaya organisasi (X2) berpengaruh signifikan terhadap kepuasan kerja $(\mathrm{Y})$, dengan kriteria uji nilai Sig. $(0,000)<\alpha(0,05)$. Artinya Ho ditolak. Hal ini menunjukan bahwa budaya organisasi mempunyai nilai signifikansi atau bermakna terhadap kepuasan kerja. kompensasi (X1) dan budaya organisasi (X2) berpengaruh signifikan terhadap kepuasan kerja (Y), diperoleh nilai Sig. $0,000<\alpha(0,05)$. Hal ini berarti bahwa secara simultan terdapat pengaruh yang signifikan dari variabel bebas terhadap variabel tidak bebas. Artinya kompensasi dan budaya organisasi mempunyai nilai signifikansi dan bermanfaat terhadap kepuasan kerja.

\section{Simpulan}

Berdasarkan hasil penelitian dan pembahasan, selanjutnya akan dikemukakan kesimpulan sebagai berikut : 
a. Unsika telah memberukan kompensasi pada skala cukup baik, budaya organisasi berada pada skala setuju dan kepuasan kerja berada pada skala Puas.

b. Korelasional antara kompensasi dengan budaya organisasi memiliki hubungan yang cukup kuat, Pengaruh parsial kompensasi $\left(\mathrm{X}_{1}\right)$ terhadap kepuasan kerja (Y) yaitu sebesar 0,172 dan budaya organisasi $\left(\mathrm{X}_{2}\right)$ terhadap kepuasan kerja (Y) yaitu sebesar 0,730 , dengan demikian budaya organisasi lebih dominan dalam memberikan kontribusi terhadap kepuasan kerja dibandingkan kompensasi. Hal ini mengindikasikan bahwa para pegawai lebih dapat meningkat kepuasan kerjanya dengan meningkatnya budaya kerja.

c. Kompensasi dan budaya organisasimemiliki kontribusi terhadap kepuasan kerja (Y) sebesar 66,79\% yang signifikan.

\section{Daftar Pustaka}

Agus Dwi Nugroho, Kunartinah, 2012. Analisis Pengaruh Kompensasi Dan Pengembangan Karier Terhadap Kepuasan Kerja Dengan Mediasi Motivasi Kerja (Studi pada PNS di Sekretariat Daerah Kabupaten Pekalongan). Jurnal.

Dhanny Permana (2008) Pengaruh Kompensasi, Kinerja Dan Budaya Organisasi Terhadap Kepuasan Kerja Karyawan PT. Mulya. Universitas Padjadjaran. Bandung

Hasibuan, Malayu S. P. 2008. Manajemen Sumber Daya Manusia. Jakarta: PT. Bumi Aksara

Koesmono, (2005). Pengaruh Budaya Organisasi Terhadap Motivasi dan kepuasan Kerja Serta Kinerja Karyawan. Jurnal Manajemen dan Kewirausahaan, Vol. 7, no. 2, September 2005

Kreitner dan Kinicki (2005:323). Organizational Behavior. Fifth Edition. McGraw Hill. New York.

Luthans, Fred. 2006. Perilaku Organisasi. Cara Mengukur Kepuasan Karyawan. Cetakan Kedua, Penerbit. PT. Elex Media Komputindo, Jakarta.

Moorse dalam Panggabean (2002:128). Manajemen Sumber Daya Manusia. Bogor. 
Nelson, D.L dan J.C. Quick, 2006, Organizatonal Behavior Foundations Realities and Challenges, Thompson South Western, United States of America.

Robbins, Stephen P. dan Timothy A. Judge. 2008. Perilaku Organisasi Edisi ke12,. PT. Salemba Empat. Jakarta.

Soedjono, 2005 dalam Dhanny Permana, 2008). Pada penelitian Soedjono (2005)

Sugiyono, (2008), Metode Penelitian Kuantitatif, Kualitatif dan $R \& D$, Penerbit Alfabeta. Bandun

Tika, Pabundu, 2005, Budaya Organisasi dan Peningkatan Kinerja Perusahaan. Jakarta: BumiAksara

Veithzal Rivai, 2008, Manajemen Sumber Daya Manusia untuk Perusahaan, Bandung: PT. Remaja Rosda Karya. 
Sugiyono, (2010), Metode Penelitian Kuantitatif, Kualitatif dan $R \& D$, Penerbit Alfabeta. Bandung

Sugiyono, (2012), Metode Penelitian Kuantitatif, Kualitatif dan $R \& D$, Penerbit Alfabeta. Bandung

Sugiyono. (2005). Memahami Penelitian Kualitatif.: ALFABET. Bandung

Sutrisno, Edy. 2010. Manajemen Sumber Daya Manusia; Jakarta, PT Prenada Media.

Suwatno, J,Priansa, Donni (2008). Manajemen SDM dalam Organisasi Publik dan Bisnis. Alfabeta, Bandung.

Tri Eka Jauhari, (2010). Pengaruh Motivasi dan Iklim Organisasi Terhadap Komitmen Organisasi Pegawai Sekretariat Daerah Kota Batam. Tesis pada Program Pasca Sarjana Universitas Terbuka. Jakarta.

Veithzal Rivai, 2008, Manajemen Sumber Daya Manusia untuk Perusahaan, Bandung: PT. Remaja Rosda Karya.

Veithzal, Rivai dan Sagala. (2011), Manajemen Sumber Daya Manusia untuk Perusahaan. PT. Raja Grafindo. Jakarta

Wagner, John A. III dan John R. Hollenbeck (2010). Organizational Behavior : Securing Competitive Advantage. New York: Routledge. 